\title{
HOSPITALIDADE E FESTA DO ESPÍRITO SANTO: CONTRIBUTOS DA CARIDADE, MISERICÓRDIA E COMENSALIDADE.
}

\section{HOSPITALITY AND HOLY SPIRIT FEAST: CONTRIBUTIONS OF CHARITY, MERCY AND COMMENSALITY.}

\section{HOSPITALIDAD Y FIESTA DEL ESPÍRITU SANTO: CONTRIBUCIONES DE LA CARIDAD, MISERICORDIA Y COMENSALIDAD.}

SUSANA GASTAL ${ }^{1}$

\begin{abstract}
Resumo: O presente artigo, de teor ensaístico, tem como objeto a Festa do Divino Espírito Santo, comemorada em Portugal e outros países, entre eles o Brasil, onde a presença de imigrantes portugueses tenha sido significativa. Independentemente do local de comemoração, a Festa marca-se pela hospitalidade expressa na comensalidade, que parece ter na caridade e na misericórdia sua sustentação em termos de imaginário. Para percorrer tal percurso de construção de sentido, opta-se por retomar a história da festividade em Portugal e as marcas comuns da comemoração que emergem dos seus desdobramentos temporais, quais sejam, as figuras da caridade (bodo) e da misericórdia, que tecem amálgamas na comensalidade. Retomam-se, no primeiro momento, as raízes etimológicas dos termos caridade e misericórdia para, a seguir, buscar sua presença histórica na Festa. A análise parece encaminhar, considerando a Festa do Divino Espírito Santo como comemorada em Alcântara, Maranhão, que os mesmos indicadores estarão, em termos mais recentes, associados à hospitalidade religiosa.
\end{abstract}

Palavras-chave: hospitalidade; imaginários; caridade; misericórdia; Festa do Divino Espírito Santo, Alcântara-MA, Brasil.

\begin{abstract}
This essay has as object the Feast of the Divine Holy Spirit, celebrated in Portugal and other countries, Brazil among them, where the presence of Portuguese immigrants is significant. Regardless of the place of commemoration, the hospitality expressed in commensality is significant of the Feast, which seems to have important imaginary in charity and mercy. To understand significances of this imaginary, it's important to research the common meanings of the celebration that emerge in Portugal, namely the charity (bodo) and mercy and their amalgams in commensality. The etymological roots of the terms "charity" and "mercy" are taken up again in the first moment, to seek its historical presence at the Feast. Considering the Feast of the Divine Holy Spirit as celebrated in Alcântara, Maranhão, analysis seems indicate that in more recent terms the same imaginary is associate with religious hospitality.
\end{abstract}

\footnotetext{
${ }^{1}$ Doutora. Professora e pesquisadora no Programa de Pós-Graduação em Turismo e Hospitalidade (Mestrado e Doutorado), Universidade de Caxias do Sul. Bolsista Produtividade CNPq. Currículo: http://lattes.cnpq.br/0363951380330385. Orcid: http://orcid.org/0000-0001-57069672. E-mail: susanagastal@gmail.com

${ }^{2}$ Doutoranda no Programa de Pós-Graduação em Turismo e Hospitalidade, Universidade de Caxias do Sul. Professora do Instituto Federal de Educação, Ciência e Tecnologia do Maranhão (Campus Centro Histórico). Currículo: http://lattes.cnpq.br/7533752263663370 E-mail: crismesquita@ifma.edu.br
} 
Keywords: hospitality; imaginary; charity; mercy; Feast of the Divine Holy Spirit, Alcântara, Maranhão, Brazil.

Resumen: Este artículo tiene por objeto la Fiesta del Espíritu Santo, que se celebra en Portugal y otros países, Brasil entre ellos, donde la presencia de inmigrantes portugueses hay sido significativo. Independiente del lugar de conmemoración, la Fiesta se marca por la hospitalidad expresada en la comensalidad, que parece tener en la caridad y en la misericordia su sustentación en términos de imaginario. Para entender la construcción de sentido, retomamos la historia de la fiesta en Portugal y las marcas comunes de la celebración que emergen en las figuras de la caridad y la misericordia, a tejer la comensalidad. Se reanudan, en el primer momento, las raíces etimológicas de los términos caridad y misericordia para, a continuación, buscar su presencia histórica en la Fiesta. El análisis parece encaminarse, considerando la Fiesta del Divino Espíritu Santo como conmemorada en Alcántara, Maranhão, que los mismos indicadores estarán, en términos más recientes, asociados a la hospitalidad religiosa.

Palabras clave: hospitalidad; imaginaria; la caridad; merced; Fiesta del Divino Espíritu Santo, Alcántara-MA, Brasil.

\section{INTRODUÇÃO}

Em artigo anterior sobre as festas em honra ao Divino Espírito Santo, as autoras partiam do pressuposto de que a religião é construção ordenadora das atividades humanas, não raro uma forma de guarida frente às mazelas do cotidiano, levando a que a festa religiosa se dê como demonstração de fé, de escape e de liberação de sentimentos, ou ainda como momento de agradecimentos por benesses recebidas. Seguia-se Geertz (1957, p. 4), para quem a religião é "sistema de símbolos que estabelece sentimentos e motivações poderosos, penetrantes, duradouros, pela formulação de concepções de uma ordem geral de existência”, podendo variar em termos de ritual e modos de adoração, assim como nas particularidades do festejar, em cada sociedade. Entretanto, no caso das festas religiosas, cada uma delas apresenta marcas comuns, na forma de imaginários compartilhados, que garantem a continuidade na diversidade (GASTAL, GOMES, 2017; GOMES, GASTAL, CORIOLANO, 2015).

Entende-se por imaginário o proposto por Maffesoli (2001), que o vê na figura de um reservatório motor, ou seja, um 'depósito' em que se acumulam lembranças e experiências, leituras de vida, imagens percebidas, que alimentam sentimentos em termos de modos de ver e agir, os quais, por sua vez, impulsionam modos de ser e de estar no mundo. Silva (2003, p. 12) complementa que "o imaginário é uma distorção involuntária do vivido que se cristaliza como uma marca individual ou grupal. Diferente do imaginado - projeção irreal que poderá se tornar 
real - o imaginário emana do real, estrutura-se como ideal e retorna ao real como elemento propulsor". Para Gastal (2005), os imaginários falam de sentimentos, de desejos e de necessidades humanas, individuais ou coletivas.

Para percorrer o percurso de construção de sentido dos imaginários associados à Festa do Divino Espírito Santo, opta-se por retomar sua história e as marcas comuns da comemoração que emergem dos seus desdobramentos temporais, quais sejam, as figuras da caridade (bodo) e da misericórdia, que tecem amálgamas na comensalidade e, e em termos mais recentes, na hospitalidade. Retomam-se, no primeiro momento, as raízes etimológicas dos termos caridade e misericórdia para, a seguir, buscar sua presença histórica na festa. Num segundo momento, os mesmos termos serão justapostos à comensalidade, para finalizar com as tessituras envolvendo a hospitalidade na Festa do Divino Espírito Santo. Destacam-se no estudo empírico as comemorações realizadas em Alcântara ${ }^{3}$, no Estado do Maranhão, localizado ao norte do Brasil. Em Alcântara misturam-se heranças indígenas e africanas, ainda presentes nos cerca de cem quilombos remanescentes do período colonial escravocrata, e que mantém suas tradições ancestrais.

As comemorações em honra ao Espírito Santo são uma herança portuguesa, presente em vários pontos do Brasil, ocorrendo geralmente no mês de maio. A Festa é organizada pelo grupo de festeiros e pela Corte do Império, formado pelo Imperador (em alguns casos a Imperatriz), os Mordomos-Régios, o Mestre-Sala ${ }^{4}$ e os Vassalos (as personagens variando de acordo com o lugar). No caso de Alcântara, paramentam-se com trajes que reportam ao figurino aristocrático do Brasil Colonial. O rito inicial acontece no Sábado de Aleluia, quando há o anúncio do dia em que o Imperador ou a Imperatriz recepcionarão os convidados, com mesa farta. No domingo de Pentecostes há o cortejo de exaltação e a elevação da Bandeira e queima de fogos, e o esmolar em favor ao Divino, para o recolhimento de donativos. No segundo sábado, se dá a distribuição de esmolas aos idosos. No último domingo, há missa solene, seguida de procissão com a Coroa do Divino, retorno à igreja e indicação dos festeiros do ano seguinte. A festa adquire contornos próprios e variações amoldadas aos costumes locais, não se podendo, desta forma, engessa-la em um único script.

Em todos os momentos dos festejos estão presentes a caridade e a misericórdia.

${ }^{3}$ Cidade Histórica e Monumento Nacional, pelo Instituto do Patrimônio Histórico e Artístico Nacional [IPHAN], em 22 de dezembro de 1948.

${ }^{4}$ Adulto responsável pela orientação dos festeiros e cumprimento das obrigações. Em Alcântara, as escolhas do Império são feitas e anunciadas pelo Mestre-Sala, que é denominado Mestre-Sala-Mor. 


\section{ESPÍRITO SANTO, CARIDADE E MISERICÓRDIA}

Caridade e misericórdia são duas palavras importantes para compreender a Festa do Divino Espírito Santo. Um passeio linguístico-semântico ${ }^{5}$ coloca a palavra caridade [caritate] como originada na latina carus, que designa alguém querido e de grande apreço. Caritas, na mesma origem, significaria afeto e amor, em afinidade, entre outras, com carícia. A origem mais remota estaria no grego chàris, significando graça, da qual derivaria carisma, que na "teologia católica é dom do Espírito Santo a serviço da comunidade" (CREVELIN, 2017, p. $11)$.

No português, caridade ganha sentido de altruísmo ou o de buscar fazer de forma altruísta, sem esperar por tal ação, qualquer recompensa, levando a sua associação à esmola. "Semanticamente [...] a conexão estreita entre caridade e hospitalidade se manifesta pelo fato de que, em um ato concreto de acolhimento, a palavra caridade pode, desde o século XII, designar uma 'refeição leve oferecida aos viajantes em um mosteiro" (ROUSSEL, 2011, p.381). Nos mesmos termos, portanto, é possível aproximar caridade e misericórdia como imaginários associados à comensalidade religiosa, o que será retomado adiante, e esta última como imaginário fundante das comemorações do Divino Espírito Santo.

Retomando Roussel (2011, p. 381), este afirma que no período medieval, quando se consagra o desenho da festa em estudo, a "importância da caridade se manifesta em especial na acolhida aos pobres. 'Aqueles que vocês chamam de pobres e mendigos, eu os proclamo senhores e auxiliares, porque são eles que poderão verdadeiramente nos auxiliar e nos dar o reino do céu', declara São João [...]”. A doutrina católica colocará a caridade como uma das sete virtudes ${ }^{6}$ a serem seguidas pelos fiéis. Associada à caridade está a dádiva (do latim donum), no seu sentido de oferenda aos deuses. Na tradição cristã supõe desprendimento, em “identificação extrema com o espírito de caridade" (PERROT, 2011, p. 613).

Misericórdia, por sua vez, seria uma aproximação entre miser [miséria] e cor [coração], no sentido de compaixão.

\footnotetext{
${ }^{5}$ Utiliza-se KOEHLER S.J., $P^{\mathrm{e}}$ H. Dicionário Escolar Latino-Portugues. Porto Alegre: Globo, s.d.

${ }^{6}$ As sete virtudes incluem: Fé, Esperança, Caridade, Sabedoria, Fortaleza, Temperança e Justiça (CREVELIN, 2017).
} 


\begin{abstract}
Misericórdia é uma tradução frequente da palavra hebraica ra.hhamím e da grega é.le.os (verbo: e.le.é.o). Um exame destes termos e do seu uso ajuda a trazer a lume seu pleno sabor e significado. O verbo hebraico ra.hhám é definido como significando 'inflamar-se, acalorar-se com terna emoção; [...] ser compassivo'. [...] segundo o lexicógrafo Gesenius: 'A ideia primária parece ser a de acalentar, acalmar, e de suave emoção mental.' [...]. O termo é aparentado de perto com a palavra para 'madre' ('ventre') ou pode referir-se às 'entranhas', que ficam afetadas quando se sente cordial e terna comiseração ou compaixão. ${ }^{7}$
\end{abstract}

Assim, no corpo físico, coração, ventre e entranhas estão semanticamente implícitos na palavra misericórdia, permitindo aproximações também aos primórdios pagãos (e mais atávicos) das Festas do Divino, relacionadas “com as celebrações da Idade Média realizadas em agradecimento à terra e à colheita, elementos que, de certa forma, influenciam suas mais variadas reformulações ao redor do mundo, independentemente do sentido ora recriado" (ANGELO, 2017, p. 424), momento em que a comida seria farta e consumida em ambiente festivo graças a generosidade do ventre da terra.

No plano espiritual, a raiz hebraico-grega da palavra misericórdia reportando a ternura, compassividade e acalanto, aproxima-se do que Angelo (2017, p. 424) também aponta em raízes mais remotas na Festa do Divino na prática do "bodo aos pobres [que] se deu entre 936 e 1218, na dinastia dos Ottons", ou seja, nos Estados Alemães, praticadas para "lançar fundamentos de uma instituição que, à maneira de um banco, formado de esmolas, acudisse aos pobres nos anos de penúria. E, como os invocantes eram reis, os festejos conservaram aspectos de realeza" (Idem, p. 425).

Assim como a questão da fome, que permeia a organização de comemorações dos ciclos agrícolas, era a busca pelo alimento o princípio dos festivais na antiguidade. Partia-se da sequência das estações do ano para fomentar os festivais, que foram, no curso da história, sendo modificados, com a incorporação de outros elementos e intenções. O cerne dos festejos, contudo, é sempre o mesmo: a comida e a fartura do alimento. Entre os festivais judaicos um dos principais era o da colheita que se realizava cinquenta dias depois da Páscoa judaica, correspondendo ao nosso Pentecostes. Enquanto na religião cristã comemora-se a descida do Espírito Santo sobre os Apóstolos, os hebreus comemoravam a colheita no dia santo que a tradição atribuía ser o dia da chegada dos Dez Mandamentos (ANGELO, 2017, p. 425).

Como colocado, ao longo da Idade Média a Festa do Espírito Santo é cristianizada.

'Mês de Maria' procurava substituir as festas de Afrodite, durante as quais os portugueses penduravam 'giestas à porta' para comemorar a fartura e o culto do reflorescimento da terra. As festas do 'Divino', propositadamente comemoradas em

${ }^{7}$ Disponível em https://wol.jw.org/pt/wol/d/r5/lp-t/1200002994 
maio, tentavam, desde D. João I, em 1385, evitar o paganismo das 'Maias', cantadas e dançadas pelas ruas (ANGELO, 2017, p. 426).

$\mathrm{Na}$ transposição do paganismo para o cristianismo, a festa agora, reformulada, mantem seu caráter de fartura e encenação: "Os festivais trazem a mesma tônica em todas as civilizações, mudando certas características segundo os costumes de cada lugar. No entanto, o alimento se encontra no cerne das festas de todos os povos enquanto elemento folclorizado e das tradições profanas" (Idem, p.427). Miranda (2016, p.4) traz um esclarecimento importante, para entendimento do que segue:

[...] o Culto ao Espírito Santo remonta à Idade Média, sendo que atribui-se a origem lusa do culto ao monge circense Joaquim de Fiori (1135 - 1203), que pregava o tempo novo do Espírito Santo, tempo este que traria amor, paz, esperança e caridade. A este monge, ainda se atribui a fundação da ordem franciscana. Entretanto, essa prática religiosa não foi bem aceita pela igreja oficial, que era ao mesmo tempo, acumuladora de bens e fechada. Desta forma, muitos adeptos do culto ao Divino Espírito Santo nesse período tiveram como punição pelas heresias acometidas por eles a morte na fogueira $[\ldots]$.

As versões mais populares e divulgadas sobre as origens da Festa do Divino Espírito Santo, entretanto, associam-na à Rainha Isabel de Aragão, casada com D. Diniz. A rainha fundou os hospitais de Rocamador e Torres Vedras (1310), dos Meninos de Santarem (1321) e o Hospital do Divino Espírito Santo (1320), em Alenquer. Ressalte-se, D. Diniz havia criado a Irmandade de Nossa Senhora da Piedade, reza a tradição, atendendo pedido da esposa, cuja função seria a de enterrar os mortos, cuidar dos doentes e dos pobres e assistir aos condenados, entre outros (IVAMOTO e al, 2017). São ações como estas que levam a canonização da rainha em 1625, passando a ser reconhecida como Santa Isabel. ${ }^{8}$

A Irmandade de Nossa Senhora da Piedade teria originado a criação das

[...] Irmandades da Misericórdia [e, por analogia, das Santas Casas de Misericórdia que], como a maioria das instituições portuguesas, tinham um forte conteúdo religioso e funções espirituais além dos 'corpóreos'. Eles foram formados por membros voluntários da comunidade local, e seus conselhos administrativos foram liderados por altos funcionários da administração pública, profissionais de prestígio ou cidadãos ricos, sendo independentes das autoridades civis ou eclesiásticas. Com o passar dos séculos, perderam suas funções espirituais e, particularmente no Brasil, se dedicaram quase que inteiramente à assistência médica e hospitalar, além de outros serviços de natureza social (IVAMOTO e al, 2017, s.p, tradução das autoras).

\footnotetext{
${ }^{8}$ A triangulação entre Joaquim de Fiore, os Franciscanos e a Rainha D. Isabel, no contexto da Festa do Divino Espirito Santo, serão tratas pelas autoras em outro momento.
} 
A página on line Portal do Divino ${ }^{9}$ traz outra informação importante, quando registra a origem das comemorações em Alenquer, Portugal, que a "fundação da igreja do Espírito Santo dessa localidade que presumivelmente se verificou no primeiro quartel do séc. XIII, se alude à festividade do Império, o que leva a supor a sua concretização aí anteriormente a 1280, promovida ou inspirada por franciscanos de tendência espiritual", anterior, portanto, a criação do Hospital pela Rainha Isabel, que só se casou com D. Diniz em 1282. "A abordagem franciscana à evangelização dos povos e as profecias de Frei Joaquim de Fiore, anunciando a nova vinda do Espírito Santo e o advento da Era do Espírito, em que todos os cristãos viveriam em paz e liberdade, diretamente inspirados por Deus e sem leis ou qualquer hierarquia, influenciaram profundamente toda acção religiosa e social de Isabel" (GENTES DA DIASPORA) ${ }^{10}$.

A Rainha, intervindo em uma festa que já existiria espontaneamente na comunidade, e que seguia em procissão pelas ruas de Alenquer, teria convocado

\begin{abstract}
[...] no dia de Pentecostes do ano de 1296, o clero, a nobreza e o povo, para tomarem parte das solenidades religiosas realizadas na inauguração de uma confraria, a que chamaram de Império. Todas as cerimônias realizadas nesse dia deveriam ser impressionantes. Desse modo, de todos os pobres assistentes aos ofícios religiosos, realizados na capela real, convidou-se o mais pobre para ocupar o dossel da capelamor, o lugar do rei, o qual lhe serviu de cortesão e os mais altos dignitários do rei lhe serviram de pajens. O pobre, então, ajoelhou-se sobre o rico almofadão destinado ao rei e, nessa postura, o bispo do paço lhe colocou sobre a cabeça a coroa real, enquanto, entoava o hino 'Veni Creator Spiritus'. Assim investido das insígnias reais, o pobre assistiu à celebração da missa. Em seguida, o pobre se dirigiu ao paço real, onde lhe foi oferecido um lauto jantar, servido pela rainha (PORTAL DO DIVINO).
\end{abstract}

Feita a coroação, o Império, agora império do espírito, estava instituído e, em tempos subsequentes, crianças passaram a ser coroadas como rei e rainha, em nome da inocência infantil. "Seguia-se uma tourada e a carne era distribuída pelos pobres, e depois o banquete ou bodo, onde abundava para todos, o pão, bolo, carne e vinho" (GENTES DA DIÁSPORA). O portal português ainda registra que entre os pobres e desvalidos protegidos pela rainha estariam os "Judeus Sefarditas"1, frequentemente perseguidos na Península Ibérica", usando sua

\footnotetext{
${ }^{9}$ Disponível em http://www.portaldodivino.com/origem/origemdafesta.htm, acesso em 12 OUT 2017.

${ }^{10}$ Disponível em http://www.adiaspora.com/_port/gentes/artigo/isabeleorigemdefestasdodes.htm, acesso em 12 OUT 2017.

${ }^{11}$ Sabe-se que desde sua chegada a 700 anos antes de Yeshua vir ao mundo até sua conversão forçada por decreto real em 1496 e exitosa sob o espanto luminoso das chamas da maldita inquisição, a mais abominável, criminosa e imunda das ações da Igreja Católica os judeus viveram e cresceram na comunidade ibérica. São 2 mil anos de coexistência nos quais a marca da presença judaica foi impressa na cultura, na língua e mesmo nos costumes
} 
influência para tal. Angelo (2017, p. 425) registra que, entre "os festivais judaicos um dos principais era o da colheita que se realizava cinquenta dias depois da Páscoa judaica, correspondendo ao nosso Pentecostes". A mesma autora ainda acrescenta, o que talvez ajude na compreensão da proteção da Rainha aos judeus: "Enquanto na religião cristã comemora-se a descida do Espírito Santo sobre os Apóstolos, os hebreus comemoravam a colheita no dia santo que a tradição atribuía ser o dia da chegada dos Dez Mandamentos” (Idem).

Miranda (2016, p. 4-5) acrescenta outra importante explicação, para compreensão do real papel da intervenção da Rainha, na Festa, talvez em outra anteposição à Inquisição:

Foi preciso quase um século para que o culto ao Espírito Santo deixasse de ser prática criminosa com punição de morte na fogueira. E tal prática só foi aceita quando uma monarca aderiu ao culto. Essa monarca a desempenhar importante papel na difusão da celebração ao Divino foi a rainha santa Isabel de Aragão (1271-1336).

A partir da intervenção da Rainha Isabel, então, o desenho da festividade estaria consagrado como elementos a compor reservatório motor e dele emergindo na forma de imaginários, caridade e misericórdia. Retomando Silva (2003), ambos emanam do real religioso enquanto práticas, estruturam-se como ideal de cristandade e retornam ao real da festa como elemento propulsor, em especial na forma de comensalidade. Do desenho festivo fazem parte: a teatralização, na forma da coroação de reis e rainhas por alguns dias, a folia, "a Comilança e o Objetivo: Espírito Santo" (ANGELO, 2017, p. 427), em entrecruzamentos com <caridade> e $<$ misericórdia>, como imaginário.

\begin{abstract}
Acerca da morfologia dos festejos populares medievais, percebe-se uma estrutura que, ora contempla as práticas Sagradas, ora contempla as Profanidades, em um sincretismo que, em algumas celebrações tornam-se difícil de dissociar-se o que é religioso e o que é profano, como propões Mircea Eliade (1992). Logo, na Festa do Divino, exemple gratia, o ritual de se escolher um festeiro/imperador, organização de cortejos e feiras expositivas são práticas com raízes medievais. (MIRANDA 2016, p. $5)$.
\end{abstract}

O mesmo Miranda acrescenta (2016, p. 4-5):

É importante salientar que, as práticas religiosas portuguesas assumem, ainda na Idade Média, o formato de festa da cultura popular, definida por Bakhtin (2013) como as festas efervescentes como o carnaval. Apesar do culto do Divino ser uma celebração

portugueses. Não é sem causa que chamamos azeitona ao fruto da oliveira, chuva o regresso das águas, lavagem a limpeza das nossas roupas e ação ao produto de nossos atos. Isso fica claro quando descobrimos que oliveira em hebraico é hazeit, que regresso shuv, que branco é lavan e que hazia é ação. O que vamos vera agora é evidência de que as marcas da presença judaica na Espanha e em Portugal são muito mais profundas do que a mera linguagem que em parte também derivamos dos árabes, ela se inscreve profundamente nos nossos nomes, no nosso sangue, no nosso DNA (COMUNIDADE DE ISRAEL, s.d.). 
religiosa e formal existir-se-ia na mesma um aspecto cômico popular e público; este consagrado pela tradição, como por exemplo "as 'festas do templo', habitualmente acompanhadas de feiras com seu rico cortejo de festejos públicos (durante os quais se exibiam gigantes, anões, monstros, e animais 'sábios')” (Idem, 2013, p. 4).

Os Franciscanos divulgaram os ideais de De Fiore, em especial nos Açores e nas colônias portuguesas, em muitos casos através das festas em homenagem ao Espírito Santo. Nestas festas, o novo tempo de comunhão e fraternidade entre as pessoas é expresso de maneira simbólica, pela "fartura de alimentos, vida de solidariedade e alegria manifesta nas cores das bandeiras, fitas, músicas e danças” (RIBEIRO, 2017, p. 267).

\footnotetext{
Estas características peculiares que marcam o catolicismo popular caipira foram forjadas inicialmente no Portugal ancestral. Tendo o colono português vindo de uma terra por diversas vezes também ocupada por povos de origem religiosa dispare, compôs aos poucos uma religiosidade fortemente arraigada a festas ligadas a fertilidade, a manipulação mágica do sagrado através de ex-votos, ladainhas, romarias, novenas e uma crença em uma diversidade de santos, anjos, milagres e de mistérios envolvendo principalmente os sacramentos. É assim que, a maior parte dos elementos religiosos que veio a constituir o catolicismo rural ou rústico já fazia parte da religião popular em Portugal e foram trazidos, portanto pelo colonizador que ao emigrar, levava consigo, além das esperanças em um mundo melhor, as suas crenças religiosas (RIBEIRO, 2017, 259).
}

No Brasil, ainda segundo Ribeiro, a Festa manteve como marcas a bandeira vermelha, representando o batismo de fogo pelo Espírito Santo, a pomba branca, como o próprio Espírito, as fitas coloridas, a inversão social, mas, especialmente, a distribuição generosa de alimentos, a serem compartilhados por fieis e seus convidados.

\section{COMENSALIDADE}

Comer atende a uma necessidade fisiológica. Quando superado o fisiológico e o comer se torna um ato social e, portanto, permeado por simbolismos, adentra-se o âmbito da comensalidade. Esta envolveria princípios associados ao o que e o como [com quem] comer, assim como ao quando e onde comer, conforme esquematizado na Figura 1. O que comer supõe os ingredientes, sua obtenção e preparo, ambos com maior ou menor complexidade, conforme o contexto social, cultural ou religioso assim o determinar ou, no caso das comidas tradicionais, como o ecossistema natural e agrícola disponibilizarem à comunidade. Em termos de comensalidade, ou seja, do comer junto, o com quem implicaria necessariamente a referência a partilha grupal, nos modos de servir e degustar, estes também perpassando fazeres, rituais e simbolismos. 
Figura1: Princípios componentes da comensalidade.

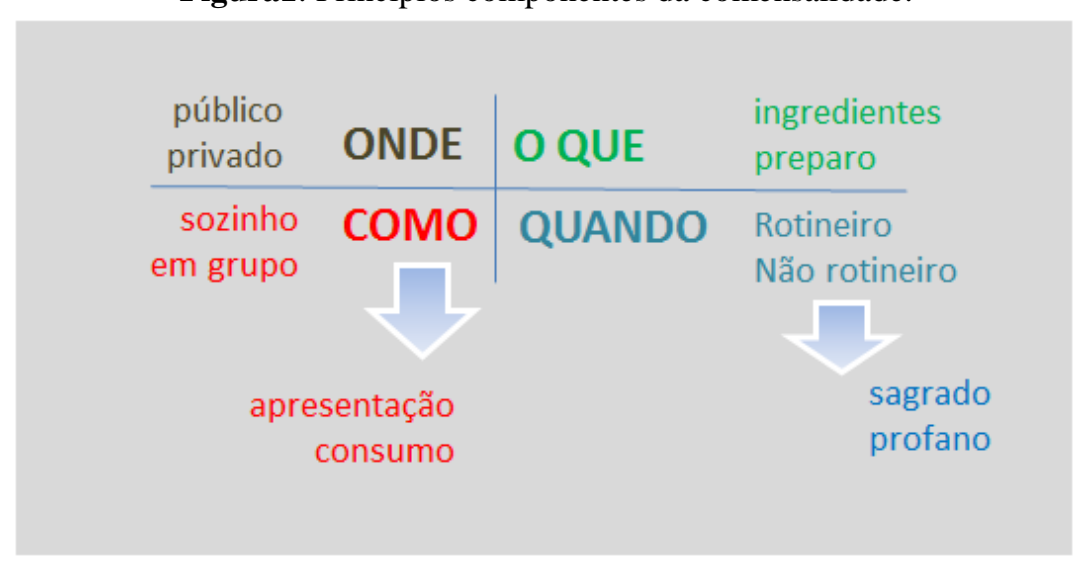

Fonte: As Autoras.

Nos princípios da comensalidade, o onde refere a que a mesma possa se dar tanto no privado (doméstico ou institucional) ou na esfera pública (institucional ou comercial), em reuniões familiares, sociais, profissionais ou religiosas, entre outras. Por fim, o quando pode demarcar tempos rotineiros, mais uma vez lembrando as refeições familiares, como exemplo, ou tempos não rotineiros, tanto no âmbito do sagrado (atos litúrgicos) como do profano, em festas sociais, cívicas, étnicas, entre outras. Em outras palavras, o fisiológico supõe comer sozinho, em público ou privado, de modo rotineiro, embora possa haver momentos não rotineiros e com ritualizações implícitas tanto na escolha de ingredientes como no seu preparo e no seu consumo. A comensalidade, por sua vez, envolveria o comer junto, em público ou privado, rotineira ou excepcionalmente. Se não rotineiramente, estes momentos podem estar associados ao sagrado ou ao profano e à festa, com especificidade de fazeres e rituais em termos de ingredientes, preparo, apresentação e consumo.

Já na sua etimologia, a palavra comensalidade "deriva do latim mensa, que significa conviver à mesa e isto envolve não somente o padrão alimentar ou o que se come mas, principalmente, como se come" (MOREIRA, 2010, s.p.), sendo, portanto, social e historicamente construída. No âmbito da comensalidade, a relação humana com o alimento permeia o espiritual, a tradição e a cultura, influenciando-as em termos de o que comer, quando e como o fazer, como preparar e como servir o alimento, contribuindo para desenvolver o que Maffesoli (2001) trata como reservatório motor, em que se organizam os imaginários, como resultado das diversas informações, experiências e percepções ali acumuladas.

Em outros termos simbólicos, Fernandes (1997) busca construir uma morfologia, em que destaca que a comensalidade apresentaria algumas marcas recorrente: aparece 
frequentemente como expressão de poder e diferencial de classe; a mesa é local de permutas sociais, tanto de companheirismo como de traições; haveria uma relação entre mesa, corpo e beleza, mesmo considerando-se que as "concepções da estética são uma função geral da mentalidade de cada época" (p.14); as religiões históricas transpõem o cerimonial da mesa para a ritualização sagrada; a comensalidade atual revelaria quebra da sociabilidade e deixaria a esfera íntima para a esfera social.

Na mesma linha de teorização, Soares e Camargo (2015) falam em duas dimensões da comensalidade: no eixo horizontal, sua força de agregação e de coesão; no eixo vertical, as hierarquias dos lugares e dos papéis. Na correlação com as religiões, apresenta-se o alimento no âmbito do sagrado e, em alguns casos, associado à caridade e misericórdia. No caso, o alimento pode se dar como memória viva, resgatando experiências e construindo identificação com um contexto coletivo, "memória como lugar de persistência, de continuidade, de capacidade de viver o insistente" (TEDESCO; ROSSETO, 2007, p. 36). Hábitos e práticas alimentares, por agregadores, contribuem para laços sociais fortalecidos, podendo sedimentar pertenças ao grupo, ao outorgar "uma identidade, reafirmada pela memória gustativa" (SANTOS, 2005, p. 5), que poderá, ainda, vir associada a raízes étnicas, de nacionalidade ou religiosas.

Assim, o simbolismo do alimento atrela-se à integração e à socialização das pessoas, da reunião familiar à memória social e coletiva. Considere-se que o "significado desses conteúdos não é interpretado pelas culturas que o praticam, mas sim cumprido como um preceito inquestionável, para o qual não são necessárias explicações” (CARNEIRO, 2005, p.72). A escolha e consumo dos alimentos podem significar tanto hábitos e costumes herdados, como a concretização de imaginários.

Nesses termos, a presente reflexão prevê retomar o percurso de sentido da comensalidade nas Festas do Divino Espírito Santo, como tendo matrizes significantes na caridade e na misericórdia, constituídas no cenário cultural e ideológico medieval. Se na sua origem pagã, a festa celebrava a colheita e o momento de fartura, em comunidades em que o alimento seria escasso, através do compartilhamento comum da comida. $\mathrm{Na}$ transposição medieval, induz-se a aproximação (simbólica) entre ricos e pobres, estes agora alimentados por um ato de boa vontade [caridade], estimulado pela prática religiosa [misericórdia], daqueles.

Considerando a figura anterior, a Figura 2 coloca em destaque, no cenário teórico até aqui descrito, em que a comensalidade, para além do comer juntos, deverá considerar: o modo 
de obtenção dos insumos para preparo dos alimentos; os modos de preparo; os modos de servir; e os de consumo; todos em termos de práticas e de rituais associados. Estes momentos são retomados a seguir, para analisar a comensalidade nas comemorações associadas ao Divino Espírito Santo, em Alcântara, no Maranhão, onde a comensalidade se dá como marca de hospitalidade.

Figura 2: Princípios da comensalidade aplicados a Festa do Divino Espírito Santo

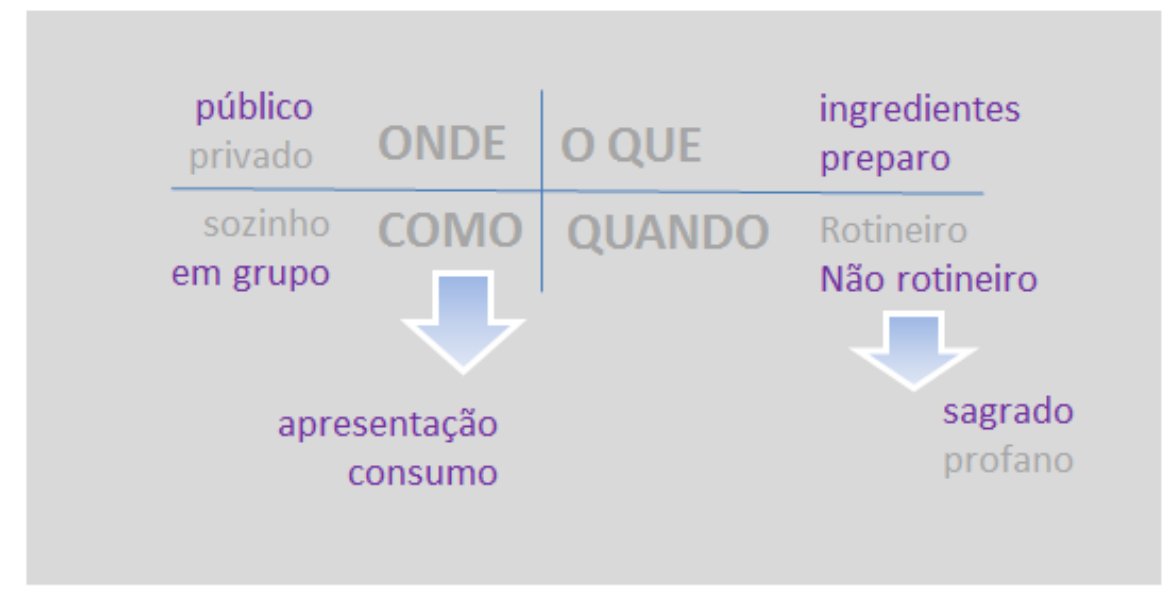

Fonte: As Autoras

\section{A FESTA DO DIVINO ESPÍRITO SANTO}

Comemorado em muitos estados brasileiros, a festa adquire contornos próprios no Maranhão, e, em especial, em Alcântara, seguindo as lógicas do catolicismo popular. As primeiras Festas do Divino, nesse Estado, reportam ao século XIX, e são descritas por Lacroix (2012, p. 222) como "festa africana associada ao culto católico, [que] reunia os participantes na beira de uma estrada ou num terreiro, com bandeirinhas de papel colorido, uma grande bandeira vermelha com a pomba simbólica do Divino Espírito Santo".

Desfilava pelas ruas, em tom festivo, o Imperador, a Imperatriz vestidos a caráter, um pagem [sic] carregando uma coroa numa salva e vários personagens até uma igreja para participarem de uma missa dominical do mês de maio. Desde os preparativos da festa até seu desmonte, voluntários ajudavam na cozinha, geralmente nos fundos da casa da festa ou nos baixos dos sobrados, preparando almoços e jantares com boi, capado, capões, galinhas, patos, bolo de macaxeira, bolo de tapioca, pão de ló, doces de espécie com figuras de animais ou corações, cardápios fartos ou modestos, conforme a ajuda de governantes e do comércio, em geral. [...] em outros pontos da cidade, à noite, protegidas pelas sombras da fraca iluminação das fumegantes lanternas de óleo de peixe, se juntavam, na maioria, negras e mulatas para certos 'excessos' e cantorias, as modas da terra, modinhas e lundus (Idem). 
$\mathrm{Na}$ atualidade, os preparativos iniciam no mês de maio ${ }^{12}$. O rito primeiro dá-se no Sábado de Aleluia, momento em que os festeiros anunciam o dia em que o Imperador ou a Imperatriz recepcionarão os convidados com grande festa, em que é servido almoço com mesa farta de doces, e para a qual todos, comunidade e visitantes, são convidados, sem que implique qualquer retribuição financeira.

Outro momento importante acontece no Domingo de Pentecostes, quando os devotos elevam a Bandeira, em cortejo de exaltação ao poder do Imperador como agente de Deus na Terra. O Cortejo do Império segue entre bailados, ladainhas e queima de fogos, projeta alegria e realiza farta distribuição de comida e bebida, realiza o esmolar em favor ao Divino, para o recolhimento de donativos que garantirão os insumos necessários a montagem da comemoração, em especial, dos alimentos destinados às comensalidades, nos banquetes. (MOURA, 2005, p. 44). No domingo é praxe a missa solene e visitas do Mordomo às casas dos festeiros. Uma semana de ladainhas precede o dia da Subida do Boi ${ }^{13}$.

No segundo sábado, há o momento da distribuição de esmolas aos idosos. No último domingo, celebra-se missa solene, seguida do cortejo de retorno à Casa do Divino, depois procissão com a Coroa do Divino e retorno à igreja para leitura do Pelouro ${ }^{14}$, em que constam os nomes dos novos participantes, para o ano vindouro. Na última segunda-feira, faz-se entrega do posto de festeiro aos novos ingressantes. Em diferentes momentos da Festa, as Caixeiras são destaque pela singularidade com que fazem soar os tambores, com toques pessoais, ditos pitorescos, que diferem daqueles de outros lugares. Em todos estes momentos os alimentos estão presentes para entreter os convidados, ou para impressioná-los, na sua generosa distribuição.

A organização da Festa é de responsabilidade do grupo de festeiros e da Corte do Império. A obtenção dos insumos necessários à preparação dos alimentos se dá através de doação e mendicância. Para promover a doação, há dois momentos, o almoço na Casa do Imperador e, outro, na casa do Mordomo, cerca de trinta dias antes do início da comemoração, mais propriamente, reunindo convidados especiais. Outra forma de arrecadação de fundos são

\footnotetext{
${ }^{12}$ Lima (2014, p.96), que estudou festas religiosas em Goiás, explica que “os meses de maio e junho é o período de celebrar a colheita e sua abundância, com a grande festa da fartura, que é a do Divino Espírito Santo [...]".

${ }^{13}$ Trata-se de cortejo pelas ruas da cidade, parte do ritual de morte e esquartejamento do boi que será servido como alimento durante a festa; a sequência do ritual é definida pelos cânticos das Caixeiras.

${ }^{14}$ Documento que anuncia os festeiros do ano seguinte.
} 
as visitas do cortejo, para benção, de casa em casa e a espaços do poder público, como a Câmara de Vereadores e a Prefeitura, buscando angariar donativos. Pessoas que por algum motivo não possam participar da Festa nos dias oficiais - membros de asilos ou creches também receberão a visita e benção especial do Divino Espírito Santo, desfrutando do privilégio de conviver com a família que compõe o cortejo do Império.

Obtidos os insumos e recursos financeiros necessários, o preparo das comidas é realizado de forma coletiva. Inicia-se pela feitura de licores e doces de espécie, nos dias anteriores ao início da Festa. Depois, as cozinheiras passam várias noites na cozinha preparando os pratos a serem servidos "aos personagens centrais da festa como o império e caixeiras, bem como a todos os participantes, uma vez que a fartura e a comensalidade são preponderantes na dinâmica do festejo" (FIGUEIREDO, 2006, p. 3). No registro de Lacroix (2012, p. 222), em tempos anteriores a participação da comunidade já era intensa, desde a montagem da festa até seu desmonte, a comensalidade incluindo "boi, capado, capões, galinhas, patos, bolo de macaxeira, bolo de tapioca, pão de ló, doces de espécie com figuras de animais ou corações, cardápios fartos ou modestos, conforme a ajuda de governantes e do comércio, em geral".

Compreende-se, na atualidade, o ato de preparar o alimento festivo como "manifestações de devoção e da retribuição às graças concedidas pelo Divino, em especial, o ato de partilhar [...] a fartura é um aspecto marcante da festa, sendo comum avistar os devotos se fartando" (VILLANOVA; PELEGRINI, 2011, p.4), implícitos a caridade e a misericórdia. Durante a festa, parte dos modos de servir, mesas de banquete ficam à disposição dos festeiros, brincantes, fiéis e moradores, em vários pontos da cidade, entre eles a Casa do Divino. Os variados pratos servidos têm em comum as mesas de doces no início e final dos festejos. Há bolos, doces de espécie, licores e outras guloseimas da tradição local, ofertados para quantos ali estejam, podendo chegar a 25 mil o número de pratos de comida servidos, nas maiores festas.

Associado aos modos de consumir, os convidados amontoam-se em torno das mesas, mas há certa hierarquia, na sua composição: “os festeiros almoçam com padre em um local privilegiado da casa da festa. A figura dos reis da celebração é colocada em destaque, afinal são considerados os mentores de toda festividade naquele ano" (VILLANOVA; PELEGRINI, 2011, p. 5). Em todos os momentos, na comensalidade a ponte para a hospitalidade. 


\title{
5 HOPITALIDADE
}

Abordar a comensalidade sob os vieses apresentados até aqui, aproxima-a da hospitalidade, considerando-a como forma de receber e de tratar com a alteridade. Como colocado por Soares e Camargo (2015, p. 193):

\begin{abstract}
Pode-se separar o prazer do alimento do prazer da companhia que se tem para o alimento, do prazer da conversação jogada fora [à batons rompus] que, para Kant (2006), é o exercício mais nobre do ser-estar humanos [...]. Neste caso, a comensalidade pode ser entendida como um tempo e um espaço da hospitalidade humana: 'O comensal assume, antes de tudo, a figura do hóspede. Ele se identifica, desse modo sob o termo genérico de convidado (isotomia da recepção) ou, de maneira mais específica, de conviva (isotopia da refeição) porque a noção de comensalidade condensa os traços da hospitalidade e os da mesa'. (Boutaud, 2011, p. 1213). Mais: a comensalidade traz embutidas duas dimensões da noção de hospitalidade humana, uma horizontal e outra vertical.
\end{abstract}

Em termos da hospitalidade religiosa, Godi (2011, p. 613) explica que na igreja primitiva, o receber organizava-se em torno do bispo. O espaço físico da casa de misericórdia era múltiplo, ao reunir local de culto e de acolhimento no mesmo complexo arquitetônico. No século IX, Esmoler, um monge experiente, é quem passa a cuidar dos necessitados à porta do mosteiro. É nessa dimensão religiosa, de ir a favor do outro, que se institui a hospitalidade como decorrência do acolhimento, da partilha, da benevolência. O lava-pés estava incurso na gentileza, assim como a refeição compartilhada e dinheiro que eram providenciados aos pobres pela condescendência dos mosteiros, "a fim de inscrever no cotidiano de cada monge o dever da caridade. Nas grandes cidades, as 'casas de Deus' estabelecidas perto das catedrais e dos palácios episcopais acolhe os indigentes e os enfermos." (CARRÉ, 2011, p. 576).

Quando aumentou consideravelmente a presença de peregrinos em direção a Roma, Jerusalém e Santiago de Compostela, além dos hospitais junto às casas episcopais e mosteiros, registra-se a presença dos asilos hospitalares, "na entrada das cidades, ao longo dos caminhos, espécies de novos xerodochia que tomarão o nome da 'santas casas' e acabarão por acolher também doentes" (GODI, 2011, p. 612). O século XII registra o nascimento das ordens religiosas "especializadas no exercício da caridade e da hospitalidade" (Idem, grifo nosso), os monges medievais, em nome da misericórdia, desempenhando papel preponderante no auxílio a esses necessitados. Os mosteiros transformam-se em espaço de acolhimento. Junto ao claustro havia, de um lado, a hospedaria dos nobres, e de outro, a hospedaria dos pobres, peregrinos e 
monges que houvessem abandonado todos os seus bens. Por esta razão, além de acolhidos deveriam ser alimentados.

"Na Inglaterra do século XVI, os monges que inicialmente davam o exemplo de hospitalidade, acolhendo pessoas estranhas sem discriminação, encarregaram capelães de organizar essa hospitalidade" (CANTO-SPERBER, 2003, p. 753), levando a que as relações entre monges e pobres fossem cada vez mais distantes, à medida que as casas para tratamento de saúde se institucionalizavam. Na atualidade, há a "expressão de outra forma de hospitalidade, não mais social, desta vez, mas espiritual e mística” (GODI, 2011, p. 613), que se insere como caridade e misericórdia.

Contextualizando a hospitalidade no ambiente da Festa do Divino Espírito Santo, há um acolhimento natural e progressivo entre visitantes e festeiros, decorrência do exercício da caridade e da misericórdia pela comunidade, o que leva a viabilizar a festa. O modo de fazê-lo, a gratuidade da comida, a manifestação e as peculiaridades na comensalidade ofertada ao Divino, aproximam os visitantes dos visitados em trocas como o descrito por Santos e Perazzolo (2012, p. 4):

No cerne da proximidade entre acolhimento e turismo estão as experiências vividas pelos sujeitos primariamente acolhidos e primariamente acolhedores, tendo como suposto que as experiências são processos que traçam as marcas da memória; que fazem convergir a formação das representações para a culminância afetiva geradora das sínteses mentais de prazer ou desprazer; e que, no conjunto, viabilizam a transformação humana. Portanto, o turista, o sujeito na condição primária de acolhimento, se sentirá tão mais acolhido quanto mais intensas forem suas experiências de prazer e de aprendizagem, desencadeadoras das mudanças vivenciadas e testemunhadas pela memória. Da mesma forma, o sujeito na condição primária de acolhedor também poderá experienciar prazer e aprendizagens promotoras de mudanças, como efeito inevitável das trocas relacionais.

Integrar o visitante é compromisso do acolhimento, sendo que a grande marca da hospitalidade, para Camargo (2004), está no receber e aceitar bem ao outro, assim como o outro deve aceitar a dádiva do acolhimento, pois a recusa pode ser encarada como ofensa. Na mesma medida, quem é recebido deve devolver a gentileza, em agradecimento, numa troca mútua que poderá prover crescimento e alargamento das relações, humanizando-as.

Retornando por onde começamos, ou seja, percorrendo concepções etimológicas, o dicionário define hospitaleira como "a irmã de caridade que trata gratuitamente de doentes, em obediência aos regulamentos de sua comunidade", enquanto que hospitaleiro significaria "aquele que oferece hospedagem por bondade ou caridade, que acolhe francamente, que 
agasalha” (HOUAISS; VILLAR; FRANCO, 2001, p.1553). No mesmo dicionário, hospitalidade seria o "ato de hospedar; acolhida de hóspedes; qualidade do que é hospitaleiro; recepção ou tratamento afável, cortês; amabilidade e gentileza" (Idem).

\begin{abstract}
A hospitalidade é não apenas um processo pelo qual estranhos são transformados em amigos, mas também, mais ainda, a qualidade pela qual ideias pouco familiares podem atravessar as fronteiras das ideias aceitas. Descobre-se a importância da hospitalidade não estudando-a como um costume social ou como expressão de um temperamento, mas sim considerando-a como um elemento essencial da eficácia intelectual e da plenitude moral (CANTO-SPERBER, 2003, p. 752).
\end{abstract}

Canto-Sperber (2003) ainda acrescenta que a hospitalidade era, na origem, também uma solução de alcance universal para os menos favorecidos socialmente, providenciando autonomia para além dos direitos instituídos no nascimento.

\title{
6 CONSIDERAÇÕES FINAIS
}

Como proposto inicialmente, procurou-se demonstrar que $o$ imaginário da comensalidade, eixo condutor das comemorações associadas à Festa do Divino Espírito Santo, alimenta-se da caridade e da misericórdia.

Nos interstícios da hospitalidade com a Festa do Divino Espírito Santo, é fundamental registrar que esta comemoração se faz presente desde sua constituição histórica, na Idade Média, e que acompanhou a expansão portuguesa para as Américas no século XVI e seguintes. Nesta condição, a Festa do Divino assumia, através da misericórdia e da caridade, importante papel no acolhimento entre colonizador e colonizado, como mediadora da apropriação dos novos espaços coloniais. Para tanto, hibridizando-se tradições indígenas e africanos às europeias, na construção do imaginário que as comemorações do Divino consagrarão.

Antes, como agora, uma das principais marcas da Festa do Divino Espirito Santo está na gratuidade e fartura dos alimentos ofertados aos visitantes, a comensalidade colocando-se como forma de dizer 'seja bem-vindo' e 'congratule conosco', em nome do Divino Espírito Santo. Nas pesquisas sobre a Festa do Divino Espirito Santo percebeu-se que, independentemente do lugar onde a comemoração se dê, a caridade e a misericórdia imiscuem-se com a comensalidade, e que esta se dá como forma de hospitalidade. A caridade e a misericórdia atualizam-se no dar, receber, retribuir, palavras reiteradamente presentes quando se busca entender os princípios da hospitalidade, nas teorizações contemporâneas. 


\section{REFERENCIAS}

ANGELO, E. R. B. As celebrações do Divino Espírito Santo: um elo entre Brasil e Açores nas relações de tradição e (res)significação da cultura. In: MENEZES, L. M.; SOUZA,F. (orgs.). Brasil-Portugal: Pontes sobre o Atlântico. Múltiplos Olhares sobre a E/Imigração. Rio de Janeiro: Eduerj/ Faperj, p. 363-377, 2017.

CAMARGO, Luiz Octávio de Lima. Hospitalidade. São Paulo: Aleph, 2004.

CARNEIRO, H. S. Comida e sociedade: significados sociais na história da alimentação. História: Questões \& Debates, n. 42, p. 71-80, 2005.

CARRÉ, J. Asilo de pobres. Entre caridade e reclusão. In: MONTANDON, A. (dir.). O livro da hospitalidade: a acolhida do estrangeiro na história e nas culturas. São Paulo: Senac, p. 575-582, 2011.

COMUNIDADE DE ISRAEL. Lista de Sobrenomes Judaico Sefarditas de Lusobrasileiros. Ji-Paraná. Rondônia Edições Comunidade de Israel. Disponível em: http://www.comunidadedeisrael.com.br/ebooks3/Oliveira\%20Brasileira.pdf . Acesso em: 15 nov. 2017.

CREVELIN, A. S. S. Quando religião e estudos de línguas se encontram: o advérbio ONDE em textos de temática religiosa. Mandinga Revista de Estudos Linguísticos, v. 1, n. 1, p. 8$19,2017$.

CANTO-SPERBER, M. Dicionário de ética e filosofia moral. São Leopoldo, RS: Universidade do Vale do Rio dos Sinos, 2003.

HOUAISS, A.; VILlAR, M. S.; FRANCO, F. M. M. Dicionário Houaiss da língua portuguesa. Rio de Janeiro: Objetiva, 2001.

FERNANDES, A. F. Ritualização da comensalidade. Repositório, Universidade do Porto, p. 730, 1997. Disponível em: https://repositorio-aberto.up.pt/bitstream/10216/9045/2/1412.pdf . Acesso em: 20 set. 2016.

FIGUEIREDO, W. "Divinos Maranhenses" no Rio de Janeiro: relações entre práticas de sociabilidade e práticas rituais: a Festa do Divino Espírito Santo do Terreiro Cazuá de Mironga em Seropédica-RJ. Textos escolhidos de cultura e arte populares, v. 3, n. 1, 2006.

GASTAL, Susana. Turismo, imagens e imaginários. São Paulo: Aleph, 2005.

GASTAL, S.; GOMES, C. M. Festas Religiosas e Cognição Popular: Uma aproximação à Festa do Divino em Alcântara (Brasil). In: Educação, Territórios e Desenvolvimento Humano: Atas do II Seminário Internacional, Porto, Portugal, p. 49-64, 2017. Disponível em: < https://bibliotecadigital.ipb.pt/bitstream/10198/14372/6/Mesquita\%20II_SIE_Atas_FINAL_we b-3.pdf> . Acesso em: 20 dez. 2017

GEERTZ, C. Ethos, world-view and the analysis of sacred symbols. The Antioch Review, v. 17, n. 4, p. 421-437, 1957.

GENTES DA DIÁSPORA. Isabel e a origem da festa do Divino Espirito Santo entre os portugueses. Disponível em: 
<http://www.adiaspora.com/_port/gentes/artigo/isabeleorigemdefestasdodes.htm>. Acesso em: 12 de out. 2017.

GODI, P. Igreja. A casa de misericórdia. In: MONTANDON, A. (dir.). O livro da hospitalidade: a acolhida do estrangeiro na história e nas culturas. São Paulo: Senac, p.605$618,2011$.

GOMES, C. M.; GASTAL, S.; CORIOLANO, L. N. Hospitalidade na Festa do Divino: seu festejar em Alcântara e São Luís do Maranhão. Revista Cenário, v. 3, n. 5, p. 87-104, 2015.

IVAMOTO, H. S. et al. History of the Misericordias. LINKS, v. 7, n. 1, 2017.

LACROIX, M. L. L. São Luís do Maranhão: corpo e alma. São Luís: Lithograf, 2012.

MAFFESOLI, Michel. O imaginário é uma realidade. Revista Famecos, v. 8, n. 15, p. 74-82, 2001.

MIRANDA, Ronyperteson Morais. Divina imagem: a Festa do Divino Espírito Santo de Pirenópolis, Goiás no documentário do Iphan. Anais dos Simpósios da ABHR, n. 2, 2016.

MOREIRA, S. A. Alimentação e comensalidade: aspectos históricos e antropológicos. Ciência e Cultura, v. 62, n. 4, 2010.

MOURA, A. P. Turismo e festas folclóricas no Brasil. In: FUNARI, P. P.; PINSKY, J. (Orgs.). Turismo e Patrimônio cultural. São Paulo: Contexto, 2005. p. 35-49.

PORTAL DO DIVINO. Origem da Festa do Divino. Disponível em: <http://www.portaldodivino.com/origem/ origemdafesta.htm>. Acesso em: 12 de out. 2017.

PERROT, D. Dadiva: hospitalidade e reciprocidade. In Montandon, A. O livro da hospitalidade. Acolhida do estrangeiro na história na cultura. São Paulo: Senac, p 63-80, 2011.

RIBEIRO, LIDICE MEYER PINTO. Contribuições da festa do Divino Espírito Santo na crença do protestantismo rural. Horizonte, v. 15, n. 45, p. 256-284, 2017.

ROUSSEL, C. Idade Média. O caminho e o peregrine. In: MONTANDON, A. (dir.). O livro da hospitalidade: a acolhida do estrangeiro na história e nas culturas. São Paulo: Senac, p. 379-416, 2011.

SANTOS, C. R. A. A alimentação e seu lugar na história: os tempos da memória gustativa. História: Questões \& Debates, n. 42, p. 11-31. 2005.

SANTOS, M. M. C.; PERAZZOLO, O. A. Hospitalidade numa perspectiva coletiva: o corpo coletivo acolhedor. RBTur - Revista Brasileira de Turismo, v. 6, n. 1, p. 3-13. 2012.

SILVA, J. M. As tecnologias do imaginário. Porto Alegre: Sulina, 2003.

SOARES, F. C.; CAMARGO, L. O. L. Produção científica sobre comensalidade no Brasil: estudo documental de teses e dissertações (1997- 2011). Revista Rosa dos Ventos-Turismo e Hospitalidade, v. 7, n. 2, p.191-204, 2015.

TEDESCO, João Carlos; ROSSETO, Valter. Festas e saberes: artesanatos, genealogias e memória imaterial na região colonial do Rio Grande do Sul. Passo Fundo: Méritos, p. 9-134, 2007. 
GASTAL, Susana de Araujo e MARTINS, Cristiane Mesquita Gomes. Hospitalidade e Festa do Espírito Santo (...). Revista Hospitalidade. São Paulo, volume 15, n.01, p. 141-160, jan-jul de

VILlANOVA, W.; PELEGRINI, S. C. A. E dos devotos do Espírito Santo. Fé e devoção: o alimento sagrado na Festa do Divino em SP. In: Anais... Congresso Internacional de História, 5, Maringá-PR, 2011. Disponível em: http://www.cih.uem.br/anais/2011/trabalhos/373.pdf . Acesso em: 10 mar. 2016.

Artigo recebido em: 10/06/2018

Avaliado em: 14/06/2018

Aprovado em: 20/06/2018 